\title{
Pedro López Morales, un empresario en la Córdoba del siglo XIX
}

\author{
M. ${ }^{a}$ José Álvarez Arza *
}

El breve estudio que aquí presentamos se incluye dentro de la corriente de investigación que, sobre historia empresarial ${ }^{1}$, se viene realizando en España ${ }^{2}$ desde hace varios años, con resultados que han contribuido a iluminar nuestra historia económica tanto a nivel regional como nacional. Su objeto es bien simple: se trata de pesar revista a las actividades económicas de un empresario ${ }^{3}$, el banquero Pedro López

* UNED.

' La citada corriente recibió un impuiso decisivo cuando Arthur $H$. CoLE -autor entre otros interesantes trabajos de "An Approach to the Study of Entrepreneurialship"; The Journal of Economic History, Supplement VI, 1946 y fundador, junto a J. Schumpeter, en 1948 en Harvard del Centro de Investigación de Historia empresarial- en su discurso de toma de posesión como Presidente de la Asociación de Historia Económica de los Estados Unidos de América, reconoció la importancia de la figura del empresario y su destacado papel en el progreso económico, dándole carta de naturaleza, asimismo, a la Historia empresarial; sobre el particular puede consultarse Cochran, T. C. "Arthur Harrison Cole, 1889-1974", Business History Review, XLIX, núm. 1, 1975; asimismo es interesante traer a colación el concepto schumpeteriano del empresario, del que nos habla CASTEJÓN, R. en «El empresario schumpeteriano y la historia empresarial», Papeles de Economia, núm. 17, págs. 160-167.

2 Destacan, entre otros, los trabajos publicados por CASTEJón. R. La Casa Carbonell de Córdoba 1866-1918. Génesis y desarrollo de una sociedad mercantil e industrial en Andalucía, Madrid 1977; García Montoro, C., Málaga en los comienzos de la industrialización: Manuel Agustín de Heredia (1786-1846), Córdoba, 1978 o el más reciente de GorTÁZAR, G. Alfonso XIII, hombre de negocios, Madrid, 1986.

${ }^{3}$ La figura del empresario ha ido mereciendo, a lo largo de los tiempos, toda una serie de adjetivos calificativos que van desde la denominación de «malvado explotador de la clase obrera" a la de "gran actor de la economía» (Hughes, J., The Vital Few, N. York, 1966), pasando por la de héroe de la vida económica" (GILDER, G., El espíritu de empresa, tr. esp., Madrid, 1986, pág. 18). No debe importarnos aquí - sería objeto de otro tipo de investigaciones no estrictamente histórico-económicas - cuál sea la imagen que del empresario tenga una determinada sociedad sino, más bien, el hecho de que estos, con errores 
Morales, que, en el segundo tercio del siglo XIX, se estableció en Córdoba $y$, con su casa de banca ${ }^{4}$, contribuyó indudablemente al desarrollo económico de la zona. Una zona, de otro lado, en la que no abundaban las instituciones financieras y de crédito ${ }^{5}$ por aquellos tiempos y en la que la economía, dado su volumen, no parecía necesitar muchas más de las que, por aquel entonces, existían ${ }^{6}$.

\section{VIDA Y OBRA DE PEDRO LOPEZ MORALES}

El banquero Pedro López Morales, llegó a la ciudad de Córdoba procedente de Aguilar del Río Alhama (provincia de Logroño), donde ha-

y aciertos, han contribuido en muchos países al bienestar de la sociedad aunque claro es, persiguiendo siempre su propio interés.

Entre los trabajos realizados, sobre empresarios o verdaderas dinastías de empresarios extranjeras, podríamos destacar, entre otros muchos, los de BouviER, J. Les Rothschild, París, 1967 - trabajo que, para España, ha sido completado por DE OTAZU, Alfonso, Los Rothschild y sus socios en España (1820-1850), Madrid, 1987 y IACCOCA, L. Y NovaK, W., laccoca. Autobiografía de un triunfador, tr. esp. Barcelona, 1985.

${ }^{4}$ Sobre la historia de los bancos privados en España, debemos señalar la existencia de excelentes trabajos como los publicados por Titos MARTinez, M., Crédito y ahorro en Granada, 2 vols., Granada, 1978 y GARCIA LÓPEZ, J. R., Los comerciantes banqueros en el sistema bancario español "Estudio de las casas de banca en Asturias en el siglo xIx, Oviedo, 1987 e ídem, "El sistema bancario español en el siglo XIX: ¿Una estructura dual? Nuevos planteamientos y nuevos problemas", Rev. Hist. Económica VI, 1, 1989, págs. 111-132.

${ }_{5}^{5}$ En Córdoba, en la segunda mitad del pasado siglo, tenían abiertas sus puertas la sucursal del Banco de España (1879), el Crédito Comercial y Agrícolo (1864-67), y la Caja de Ahorros y Monte de Piedad de Córdoba (1878), cuyos servicios eran complementados por los banqueros particulares como Ramón de Torres y Codes, Joaquín de la Torre, Luis Alberti, Jaime Aparicio Simón y otros, destacando de entre ellos Pedro López Morales, Trifón M. Aspitarte y Sres de Albors y Escalambre, según se desprende de la documentación depositada en el Archivo Histórico del Banco de España, legajo 1026.

Para conocer la situación de las instituciones financieras y crediticias andaluzas en la segunda mitad del siglo XIX puede consultarse, entre otros, TEDDE DE LORCA, P., "Burguesía, banca y mercado (1840-1874)", en BERNAL, A. M., (dir.), Historia de Andalucía VII, Barcelona, 1981, pags. 345-398; idem, «Un capitalismo precario (1874-1920), en BERNAL, A. M. (dir.), Historia de Andalucía VIII, Barcelona, 1981, págs. 161-216; Palacios Bañuelos, L. Sociedad y economía andaluza en el siglo XIX. Montes de Piedad y Cajas de Ahorros, Córdoba, 1977, 2 vols.; Tiтos, M., "Panorama general de la banca en Andalucía en el siglo XIX", Actas I CHA (Contemp) II, Córdoba, 1979; del mismo auttor, "El Banco de España en Andalucía en el siglo XIX», I CHA (Contemp), II, Córdoba, 1979, págs. 209-228; ALBORNOZ, S., "Los bancos y las sociedades de crédito en provincias 1856-1868", Moneda y crédito, 104, 1968, págs. 3984 y TORTELla, G. (dir.), La banca española en la Restauración, Madrid, 1974, 2 vols.

- Según se deduce de la carta enviada por D. A. Pardiñas al Gobernador del Banco de España, D. José Gónzalez Breto, el 27 de noviembre de 1879, que se encuentra en el Archivo Histórico del Banco de España, legajo 1026. 
bía nacido en 1814, en el seno de la familia constituida por el matrimonio de Patricio López y Apolonia Morales. En 1838, residiendo ya en Córdoba, contrajo matrimonio con la cordobesa María Luisa Amigo - que fallecería el 19 de julio de 1857- huérfana de padre y poseedora de un pequeño capital (si lo comparamos con el que contaba, por aquel entonces, su marido ${ }^{7}$ ); de esta unión nacieron ocho hijos, dos de los cuales fallecieron solteros: Luis aún menor de edad y Manuel en 1885, ya mayor de edad, pero todavía en vida de su padre ${ }^{8}$. Los hijos varones que sobrevivieron al banquero -Francisco, Rafael y Pedro- siguieron sus pasos y continuaron con los negocios de la banca, denominada a partir de 1885, Banca Pedro López e Hijos.

Hacia 1854 abandona la actividad principal que había llevado hasta ese momento - que no era otra que la de comerciante de paños- y la cede a su hijo Manuel, de 24 años, para que la explote juntamente con sus dos socios, antes dependientes de la casa: Leandro Fraile y Antonio García Jurado ${ }^{9}$. A partir de este momento el emprendedor vecino de la calle Carreteras número 14, hoy llamada Pedro López, realiza conjuntamente operaciones financieras ${ }^{10}$ y comerciales, además de las de explotación de sus propiedades rústicas y urbanas ${ }^{11}$; en el año 1864 y a raíz de la fundación del Crédito Comercial y Agrícola de Córdoba ${ }^{12}$ es nombrado director del mismo ${ }^{13}$ y más tarde, le veremos encargado de su liquidación en 1867; en este momento es ya una figura de peso en el panorama bancario cordobés y, en 1868, abre una sucursal de su casa de banca en Granada contando, además, con una importante red de

7 El documento de Dote y Declaración de capital que firman, el 6 de febrero de 1838, ante el escribano Don Mariano de Vega de la ciudad de Córdoba, nos revela que el valor de los bienes aportados por Maria Luisa Amigo ascendía a prácticamente 92.226 reales de vellón mientras que la contribución de su futuro esposo sólo alcanzaba los 16.900 .

${ }^{8}$ La declaración de herencia de estos dos hijos, fechada el 3 de julio de 1885, se encuentra en los documentos de la notaría de Sánchez Guerra, núm. 246, pág. 1261.

${ }^{9}$ Constituyeron los tres nombrados una sociedad colectiva mercantil denominada López, Fraile y García con un capital que, según balance, se elevaba a $879.378,20$ reales de vellón; estaba localizada dicha sociedad en la calle Esparteros n. 12.

${ }_{10}$ De su principal actividad, la de financiero, conocemos bastante gracias a los documentos notariales procedentes, principalmente, de la notaría de J. Sánchez Guerra, que fue el notario con que trabajó más asiduamente; también, por supuesto, gracias a los libros de la casa de banca, a los que ya haremos referencia y de los que nos hemos servido para completar el estudio del banquero/comerciante.

"Según el Resumen del inventario de los bienes de Pedro López, el 3,74\% del total de su patrimonio eran fincas rústicas y el $34,20 \%$ urbanas.

${ }^{12}$ El banquero Pedro López fue, precisamente, uno de los fundadores de esta entidad.

${ }^{13}$ Escritura de 1 de mayo de 1865 del notario Sánchez Guerra, que se encuentra en el Archivo de Protocolos de Córdoba. 
corresponsales situados más allá de los límites de las provincias andaluzas ${ }^{14}$. Todavía dentro de su actividad bancaria hay que reseñar sus nombramientos, en abril de 1873, de representante del Banco Hipotecario Español y, en agosto del mismo año, de Comisionado del Banco de España en Córdoba ${ }^{15}$, banco del que en 1879 será nombrado Administrador de su sucursal ${ }^{16}$.

En 1853, empieza a interesarse por ocupar el puesto que le corresponde en la sociedad cordobesa e ingresa en el Círculo de la Amistad ${ }^{17}$, del que será directivo, en varias ocasiones, desde 1859. Años después, concretamente en 1870, encajando perfectamente su personalidad de empresario con la posición social que se había ido construyendo dentro de la citada sociedad, comienza a acariciar la idea de edificar un teatro en la ciudad y sus esfuerzos se hacen realidad al inaugurarse el Gran Teatro de Córdoba en el mes de abril de $1873^{18}$. Asimismo, en esta

${ }^{14}$ Según se puede constatar en los balances, contaba con corresponsales tales como el Banco de Málaga, el de Jerez, el de Oviedo, el de Castilla, el Crédito Valenciano e, incluso, hemos encontrado en las cuentas referencias al Crédito Lyonés y al Banco de Londres; también hallamos nombres de empresarios bien conocidos como Martín Larios, Heredia, Félix Saenz o Antonio Carbonell.

${ }^{15}$ Diario de Córdoba de 26 de abril y 20 de agosto de 1873 respectivamente; asimismo, gracias a la documentación existente en el Archivo Histórico del Banco de España sobre las sucursales, conocemos la existencia de una carta que Pedro López Morales dirigió al señor Gobernador del Banco de España el 9 de septiembre de 1873; en ella le comunica la situación en que se encuentra, una vez que ha sustituido al Comisionado anterior, es decir, a don Joaquín de la Torre (legajo 1135 de la Sección de Secretaría). paña.

${ }^{16}$ Documento del Legajo 1028 de Secretaria del Archivo Histórico del Banco de Es-

17 Desde la segunda sesión; la primera, que fue constitutiva, se había celebrado el 24 de diciembre del mismo año, es decir, tres días antes.

${ }_{18}$ La construcción de este edificio pasa por dos etapas; en un primer momento, 1870 , fue promovida por un grupo de cordobeses, entre los que se encontraba el propio Pedro López, encabezados por el marqués de Gelo; un año más tarde, en 1871, se hace cargo de la misma, personal e individualmente, el propio banquero y, a partir de este momento, las obras progresan sin parar hasta la fecha de su inauguración que, según El Diario de Córdoba, tuvo lugar el 15 de abril de 1873. De las fuentes contables -Diario de la Banca de Pedro López número 26- y notariales - Escritura de aprobación de bienes, notaría de Sánchez Guerra folio 5172, documento número 1325 - se deduce que el solar sobre el que se elevó el Gran Teatro había sido adquirido por Pedro López a Don Juan de la Cruz Fuentes de la Plaza, el 16 de marzo de 1871; en 1873, una vez finalizada su construcción, su costo era de 1.386.674,89 reales; en 1892, cuando se hace el reparto de su herencia, estaba valorado, incluyendo el mobiliario, en 262.400 pesetas.

Este teatro, el único que de su categoría se ha construido en la capital cordobesa, le proporcionó a su propietario, como seguramente era su intención que sucediera, beneficios sociales y económicos. A propósito de los económicos, más tangibles y por lo tanto más fáciles de cuantificar, estamos en condiciones de asegurar que obtuvo, durante el período que lo explotó - $1873 / 1889$-, un beneficio de 60.449 pesetas; la rentabilidad de lo invertido 
década, vemos surgir su faceta de hombre público y político; en 1870 forma parte de la Junta municipal para la elaboración del presupuesto de ese año ${ }^{19}$ y se presenta por el partido monárquico progresista como candidato a diputado provincial en 1871, aunque pierde por 5 votos, que son los que le separan de su rival Amadeo Rodríguez ${ }^{20}$. Tampoco llegó a ocupar escaño en el Senado, al que pudo optar por ser uno de los treinta primeros contribuyentes de la provincia por el .concepto de Impuesto Industrial ${ }^{21}$; sí que formó parte en cambio, como Depositario, de la Junta de Gobierno de la Liga Española de Contribuyentes de Córdoba (fundada en 1873) bajo la presidencia del Conde de Torres-Cabrera ${ }^{22}$ y de la Junta de Sanidad de la provincia de Córdoba para el bienio 1871$72^{23}$.

El mayor logro de este cordobés de adopción, que no de nacimiento, fue la fundación de la banca que durante mucho tiempo llevó su nombre y que, después de su muerte, gestionaron sus hijos varones que le sobrevivieron ${ }^{24}$. La vida empresarial del banquero y la de su banca siguen destinos paralelos hasta el fallecimiento del primero; efectivamente, durante el período comprendido entre 1866 y 1884, la entidad financiera fue de propiedad exclusiva de su fundador, Pedro López Morales, quien a partir del 1 de enero de 1885 pasó a ser el socio mayoritario de una recién fundada Sociedad Regular Colectiva cuya razón social rezaba Banca Pedro López a Hijos; esta situación la compaginará con la de empresario dedicado a las finanzas, aunque en pequeña escala, y con la administración de las fincas que quedan en su poder tras la constitución de la mencionada sociedad.

Una vez conocida la vida del banquero debemos dedicar la parte final de esta comunicación a hacer una breve referencia de las cuentas de la Casa de Banca de Pedro López, más tarde denominada, como acabamos de ver, Banca Pedro López e Hijos; para ello hemos localizado, catalogado y ordenado los fondos documentales ${ }^{25}$ de la empresa,

se elevó al $17,6 \%$, cantidad nada despreciable si la comparamos con la que obtuvo con su empresa bancaria en su conjunto.

${ }^{19}$ Diario de Córdoba, 5 de julio de 1870.

${ }^{20} \mathrm{Ibidem}, 5$ de febrero de 1871.

21 Diario de Córdoba, 8 de febrero de 1871.

22 Véase PALACIOS, L. BAÑuelos, Sociedad y economía andaluzas, I, pág. 98

${ }_{23}$ Aparece nombrado en el Diario de Córdoba el día 17 de febrero de 1871.

${ }^{24}$ En su testamento, no obstante, deja la casa de la calle Carreteras número 14 a sus hijos varones y a su hija Apolonia para que, todos ellos, prosigan con los negocios de banca.

${ }^{25}$ Diarios, para la mayoría de los años del período estudiado, y Mayores para algunos. 
que hoy se encuentran depositados en el Archivo del Monte de Piedad y Caja de Ahorros de Córdoba; de estos fondos debemos lamentar únicamente la pérdida de los documentos correspondientes al año 1881. En ellos observamos que el Capital ${ }^{26}$ de la banca - que durante los 25 primeros años coincide con el del banquero puesto que no distingue entre la contabilidad familiar y la empresarial- va a ir en aumento, en líneas generales, gracias a la obtención de buenos resultados ${ }^{27}$; asimismo la rentabilidad va a ser aceptable ${ }^{28}$ y los ratios de liquidez y de tesorería, por citar algunos de los que miden la liquidez a corto plazo ${ }^{29}$, nos ratifican en la idea de una rentable empresa en expansión que puede hacer frente a un gran número de obligaciones en un corto espacio de tiempo; poco más podemos añadir a esta rápida visión de una banca que posibilitó que su dueño, que, en 1838 contaba con tan sólo 16.900 reales de vellón de capital ${ }^{30}$, al morir dejase un patrimonio que se elevaba a 2.369.923 pesetas $^{31}$. Así, tan escuetamente, se podría resumir la vida de

${ }^{26}$ Tanto los Balances como las Cuentas de Pérdidas y Ganancias se encuentran reproducidos y estudiados en nuestra Tesis doctoral inédita La banca privada en el siglo xix: Un estudio económico de las actividades del banquero Pedro López Morales (1866-1890), leída en la Facultad de CC.EE. y EE. de la Universidad Nacional de Educación a Distancia en el año 1989.

27 Los resultados provienen principalmente de la actividad financiera puesto que el año en que el porcentaje fue menor - 1873 - suponían el 59,95\% de los totales; otros años, como por ejemplo 1878 o 1880, incluso, tuvieron que compensar pérdidas sufridas en las otras dos actividades. Este éxito de la citada actividad puede estar basado, en gran parte, en la situación por la que pasaba el mercado financiero cordobés; después de 1867 en que desaparece el Crédito Comercial y Agrícola de Córdoba, las operaciones propias de la banca comercial quedarán en manos de banqueros particulares, entre los que destaca Pedro López.

${ }^{28}$ Sobre todo si se tiene en cuenta que es la obtenida después de pagar, incluso, los gastos particulares del banquero por la razón, antes apuntada, de que no distinguía entre la contabilidad familiar y la empresarial.

29 Tengamos presente siempre que estamos hablando de una casa de banca.

30 Por supuesto que el capital, tras su matrimonio con Maria Luisa Amigo, se elevó notablemente.

${ }^{31}$ La distribución del patrimonio de Pedro López, según el Cuaderno de Particiones de la notaría de Sánchez Guerra, era el siguiente:

Estructura patrimonial de Pedro López Morales a su fallecimiento (1890)

\begin{tabular}{|c|c|c|}
\hline & Ptas. & $\%$ s/total \\
\hline Metálico & $1.440 .829,32$ & 60,80 \\
\hline Mobiliario $\ldots \ldots \ldots \ldots \ldots \ldots \ldots \ldots \ldots$ & 25.035 & 1,06 \\
\hline Fincas rústicas $\ldots \ldots \ldots \ldots \ldots \ldots \ldots \ldots$ & $88.666,66$ & 3,74 \\
\hline Fincas urbanas $\ldots \ldots \ldots \ldots \ldots \ldots \ldots$ & $810.516,53$ & 34,20 \\
\hline Censos $\ldots \ldots \ldots \ldots \ldots \ldots \ldots \ldots \ldots \ldots$ & 2.000 & 0,08 \\
\hline Acciones $\ldots \ldots \ldots \ldots \ldots \ldots \ldots \ldots$. & 2.875 & 0,12 \\
\hline Total & $2.369 .922,51$ & 100 \\
\hline
\end{tabular}


este empresario y de la empresa que fundó en una región que no era la que le vio nacer, pero sí en la que se dieron cita, durante el siglo XIX un buen número de logroñeses que, al igual que Pedro López, destacaron en el mundo empresarial ${ }^{32}$.

${ }^{32}$ Como es el caso de los empresarios establecidos en Málaga Martín Larios, Félix Saenz o Manuel Agustín de Heredia sobre el último de los cuales contamos con el libro de C. García Montoro ya citado. 